\title{
Association of cytochrome P450 genetic polymorphisms with neoadjuvant chemotherapy efficacy in breast cancer patients
}

Tatyana A Seredina ${ }^{*}{ }^{\dagger}$, Olga B Goreva ${ }^{\dagger}$, Valeria O Talaban ${ }^{\dagger}$, Alevtina Yu Grishanova ${ }^{\dagger}$ and Vyacheslav V Lyakhovich $^{\dagger}$

\begin{abstract}
Background: The enzymes of the cytochrome P450 family (CYPs) play an important role in the metabolism of a great variety of anticancer agents; therefore, polymorphisms in genes encoding for metabolizing enzymes and drugs transporters can affect drug efficacy and toxicity.

Methods: The genetic polymorphisms of cytochrome P450 were studied in 395 patients with breast cancer by RLFP analysis.

Results: Here, we studied the association of functionally significant variant alleles of CYP3A4, CYP3A5, CYP2B6, CYP2C8, CYP2C9 and CYP2C19 with the clinical response to neoadjuvant chemotherapy in breast cancer patients. A significant correlation was observed between the CYP2C ${ }^{*} 2$ polymorphism and chemotherapy resistance $(\mathrm{OR}=4.64$; Cl 95\% = $1.01-20.91$ ), as well as between CYP2C9*2 heterozygotes and chemotherapy resistance in women with nodal forms of breast cancer and a cancer hereditary load $(O R=15.50 ; \mathrm{Cl} 95 \%=1.08-826.12)$ when the potential combined effects were examined. No significant association between chemotherapy resistance and the other examined genotypes and the potential combined clinical and tumour-related parameters were discovered.
\end{abstract}

Conclusion: In conclusion, CYP2C9*2 was associated with neoadjuvant chemotherapy resistance $(\mathrm{OR}=4.64 ; \mathrm{Cl}$ $95 \%=1.01-20.91)$ in the population of interest.

Keywords: Cytochrome P450 genetic polymorphisms, Neoadjuvant chemotherapy efficacy, Breast cancer

\section{Background}

Individual variability in drug efficacy and toxicity resulting in different clinical responses is common in therapeutic areas, including breast cancer. It is an important problem in clinical practice because it can lead to therapeutic failure and adverse effects. A wide variety of factors may influence drug availability and drug response, such as race, sex, diet, differences in drug pharmacokinetics and pharmacodynamics, etc. However, the importance of all of these factors is secondary to the effect of polymorphisms in drug metabolizing enzymes, drug transporters and drug targets. Polymorphisms in the genes encoding enzymes responsible for the metabolism of drugs and other xenobiotics and the

\footnotetext{
*Correspondence: tatyana.seredina@gmail.com

${ }^{\dagger}$ Equal contributors

Department of Xenobiochemistry, Institute of Molecular Biology and Biophysics of Siberian Branch of the Russian Academy of Medical Sciences (RIMBB SB RAMS), 2, Timakova str, Novosibirsk 630117, Russia
}

functional significance of these polymorphisms are critical for predicting clinical outcomes [1-3].

The members of the cytochrome P450 superfamily are involved in phase I of the xenobiotic metabolizing process. These enzymes catalyze the oxidation of many exogenous and endogenous compounds and are responsible for the metabolism of approximately $90 \%$ of clinically prescribed drugs. The CYPs are known to be involved in the metabolism of many anticancer drugs, including cyclophosphamide, 5-fluorouracil, adreamicin, xeloda, ifosfamide, etoposide, paclitaxel, etc. [4]. It was recently shown that the prodrug cyclophosphamide is activated by CYP2B6, CYP2C9 and CYP2C19 and is inactivated by CYP3A4 and CYP3A5 [5]. Xeloda is metabolized by CYP2B6, CYP2C8 and CYP2C9, while adreamicin and methatrexane are metabolized by CYP3A4 $[4,6]$.

Polymorphisms in genes encoding for metabolizing enzymes and drug transporters can affect drug efficacy and

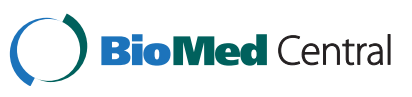


toxicity. CYP2C8 and CYP2C9 are considered highly variable genes and have more than 14 and 34 polymorphic alleles, respectively (www.imm.ki.se/CYPalleles). Most of the $C Y P 2 C 9$ polymorphisms are known to decrease the enzymatic activity of the enzyme. The CYP2C8*3, CYP2C9*2 and $C Y P 2 C 9 * 3$ polymorphic alleles frequently occur among Caucasians and lead to non-synonymous mutations, which result in decreased activity of CYP2C8 and CYP2C9 [7]. The CYP2C8 enzyme is involved in the metabolism of cyclophosphamide, ifosphamide and paclitaxel, while CYP2C9 metabolizes cyclofosphamide, ifosphamide and tamoxifen and activates tegafur $[5,8]$.

At least 28 CYP2C19 variant alleles have been previously described (www.imm.ki.se/CYPalleles), 9 of which encode for inactive enzymes. Mutations in exon 5 (CYP2C19*2) and exon $4(C Y P 2 C 19 * 3)$ are the most common polymorphisms. Both CYP2C19*2, which causes a 40nucleotide deletion and a frameshift, and CYP2C19*3, which leads to a premature stop codon, result in the production of a truncated protein without enzymatic activity [9]. CYP2C19 plays a role in the metabolism of the anticancer drugs cyclofosphamide, ifosphamide, tamoxifen and thalidomide [8].

CYP2B6 may have as many as 29 polymorphisms, but only $C Y P 2 B 6 * 5$ and $C Y P 2 B 6 * 7$ are likely to be functionally significant and result in decreased enzymatic activity $[10,11]$. CYP2B6 is involved in the activation of anticancer drugs such as cyclophosphamide and ifosphamide [5].

CYP3A is the P450 cytochrome with the widest range of drug substrates. For the majority of people, it is also the most abundant cytochrome in the liver. CYP3A4 activity has a wide range of individual activity, up to a 40 -fold difference, which may be related to the individual's health status, environment, hormones or genetics. Over 30 CYP3A4 alleles have been described, including 18 associated, nonsynonymous mutations (www.imm.ki.se/CYPalleles). The most common allele is CYP3A4\%2, which is found in Caucasians and encodes for a protein with decreased activity. A number of upstream polymorphisms have also been detected. The most extensively studied of these is $C Y P 3 A 4 * 1 B$. This polymorphism alters the putative transcriptional regulatory element - nifidipine oxidase specific element (NFSE), which is known to be required for the expression of CYP3A4 [12]. Although the CYP3A4*1B allele was initially shown to result in a 1.5 -fold increase in transcription in vitro, subsequent reports have indicated no change in its enzymatic activity. Currently, over 11 different CYP3A5 alleles have been identified. Individuals homozygous for the $C Y P 3 A 5 * 3$ allele appear to not express a functional version of the CYP3A5 enzyme due to a cryptic splice site that results in the incorporation of intronic sequence in the mature mRNA and the production of a truncated protein due to a premature appearance of termination codon [13]. This is important in anticancer therapies as CYP3A is involved in the metabolism of many drugs, including cyclophpsphamide, ifosfamide, docetaxel, paclitaxel, etoposide, irinotecan, tamoxifen, imatenib, gefenitib and vinca-alkaloids [4].

We studied the association of the functionally significant variant alleles of CYP3A4, CYP3A5, CYP2B6, CYP2C8, $C Y P 2 C 9$ and $C Y P 2 C 19$ with the clinical response to neoadjuvant chemotherapy in breast cancer patients.

\section{Methods \\ Patients}

From 1991 to 2007, 395 women (mean age of $52.00 \pm 9.89$ ) with a morphologically confirmed diagnosis of breast cancer at stages $\mathrm{T}_{1-4} \mathrm{~N}_{0-3} \mathrm{M}_{0}$ were observed at the Tomsk Cancer Research Institute in the Tomsk Scientific Center of the RAMS. Of these, 261 were treated with one of the following neoadjuvant chemotherapies: CMF or CMXeloda (Cyclophosphamide, Methotrexate and either Fluorouracil or Xeloda), FAC (Fluorouracil, Adreamicin and Cyclophosphamide) and CAF or CAXeloda (Cyclophosphamide, Adreamicin and either Fluorouracil or Xeloda). The chemotherapeutic effect was estimated after 2-4 chemotherapy courses through ultrasonic scanning and mammography according to the World Health Organization criteria. Complete remission (CR) was observed when no breast tumour; partial remission (PR) when the reduction in the tumour area was 50-100\%; and stable disease (SD) when the tumour area was reduced $0-50$, progressive disease (PD) was recorded if the tumour area increased or if a new lesion was detected. Complete remission was achieved in $3 \%$ of the patients; the partial remission rate was $47 \%$; the stable disease rate was $46 \%$ and $4 \%$ of the patients showed progression of the disease. The patients were divided into two groups according to the results of the neoadjuvant therapy; patients classified as having CR, $\mathrm{PR}$ or $\mathrm{SD}$ formed the positive response group, while patients classified as showing PD made up the negative chemotherapy response group. The local ethical review boards approved the study protocol (Protocol N3 from 08.06.2005), and all patients provided written, informed consent before acceptance into the study in accordance with the Declaration of Helsinki.

\section{Genotyping}

The genetic polymorphisms of cytochrome P450 were studied in 395 patients with breast cancer by RLFP analysis. Genomic DNA was kindly provided by the Tomsk Oncology Center SB RAMS. Oligonucleotide primers for the CYP2B6*5, CYP2C8*2,CYP2C8*3,CYP2C19*2 and $C Y P 2 C 19 * 3$ polymorphisms and restriction endonucleases were designed using the program Vector NTI 8.0. The primers for the CYP2C9*2, CYP2C9*3, CYP3A4*2, CYP3A4*B and $C Y P 3 A 5 * 3$ polymorphisms were described earlier [1417]. All of the primer sequences are provided in Table 1. 
Table 1 Primers and restriction endonucleases for the CYP450 polymorphisms genotyping

\begin{tabular}{|c|c|c|c|c|}
\hline Polymorphism & Oligonucleotide primers & Amplicone & Restriction endonucleases & Restriction products, b.p.* \\
\hline \multirow[t]{2}{*}{ CYP3A5*3 (intron 3) } & f 5'-catcagttagtagacagatga-3' & 293 & Ssp 1 & 14812520 \\
\hline & r 5'-ggtccaaacagggaagaaata-3' & & & $(168125)$ \\
\hline \multirow[t]{2}{*}{ CYP3A4*1B (5'-NTR) } & f 5'-tccaggcataggtaaagatc-3' & 111 & Acc 36 I & 111 \\
\hline & r 5'-aatctattaaatcgcctctcac-3' & & & $(8526)$ \\
\hline \multirow[t]{2}{*}{ CYP3A4*2 (exon 6) } & f 5'-ttttttggatccattctttgtc-3' & 124 & Bst MA I & 9826 \\
\hline & r 5'-ttttaagtggatgaattacatggt-3' & & & $(124)$ \\
\hline \multirow[t]{2}{*}{ CYP2C9*2 (exon 3) } & f 5'-cactggctgaaagagctaacagag-3' & 372 & Asp S9 I & 17911974 \\
\hline & r 5'-gtgatatggagtagggtcacccac-3' & & & (253 119) \\
\hline \multirow[t]{2}{*}{ CYP2C9*3 (exon 7) } & f 5'-aggaagagattgaacgtgtga-3' & 130 & ERh I & 130 \\
\hline & r 5'-ggcaggctggtggggagaaggccaa-3' & & & $(104$ 26) \\
\hline \multirow[t]{2}{*}{ CYP2C19*2 (exon 5) } & f 5'-ccagagcttggcatattgta-3' & 230 & Sma I & 109121 \\
\hline & r 5'-gaagcaatcaataaagtcccga-3' & & & $(230)$ \\
\hline \multirow[t]{2}{*}{ CYP2C19*3 (exon 4) } & f 5'-ctgggctgtgctccct-3' & 147 & BamH I & 12819 \\
\hline & 5'-acttggecttacctggct-3' & & & $(147)$ \\
\hline \multirow[t]{2}{*}{ CYB2B6*5 (exon 9) } & f 5'-aatacccccaacataccacatc-3' & 121 & Bst F5 I & 10516 \\
\hline & r 5'-gcggggagtcagagccatt-3' & & & $(121)$ \\
\hline \multirow[t]{2}{*}{ CYP2C8*2 (exon 5) } & f 5'-aaagtaaaagaacaccaagc-3' & 167 & Kzo9 I & 696533 \\
\hline & r 5'- aaacatccttagtaaattaca-3' & & & (98 69) \\
\hline \multirow[t]{2}{*}{ CYP2C8*3 (exon 3/8) } & f 5'- aggcaattccccaatatctc-3' & 467 & BseR I & 31011146 \\
\hline & r 5'-caggatgcgcaatgaagac-3' & & & (356 111) \\
\hline
\end{tabular}

* - fragments of the wild type alleles, fragments of the mutant type alleles parentheses.

The PCR reactions were carried out in a $20 \mu \mathrm{l}$ volume and contained 1x PCR buffer, 1-2 $\mathrm{mM} \mathrm{MgCl}_{2}, 250 \mu \mathrm{M}$ dNTPs, $0.5 \mu \mathrm{M}$ primers, $2 \mathrm{U}$ Taq DNA polymerase (Medigen, Russia) and 30 ng of genomic DNA. Thermal cycling was performed using an initial denaturation time of $3 \mathrm{~min}$ at $94^{\circ} \mathrm{C}$ followed by 33 cycles of $15 \mathrm{~s}$ at $94^{\circ} \mathrm{C}, 30 \mathrm{~s}$ at $55^{\circ} \mathrm{C}$ and $30 \mathrm{~s}$ at $72^{\circ} \mathrm{C}$. A terminal extension time of $5 \mathrm{~min}$ at $72^{\circ}$ $\mathrm{C}$ was used. The reaction products were digested with the appropriate restriction endonucleases (SibEnzyme Ltd., Russia) (Table 1) for 6 hour at $37^{\circ} \mathrm{C}$. The fragments were resolved by PAGE on $10 \%$ TBE gels and were subsequently stained with ethidium bromide $(10 \mathrm{mg} / \mathrm{ml})$ to visualize the bands using the "VersaDoc System" (Bio-Rad, USA).

\section{Statistical analysis}

The allelic and genotype frequencies for all examined genes were calculated for descriptive purposes, and correlation analyses were performed to investigate the relationship between the genotypes and the neoadjuvant chemotherapy outcome. The data were analyzed using EpiInfo 6.0. Differences in the distributions of the variables were analyzed by the $\chi^{2}$ or Fisher's exact tests, where the cell numbers were less than 5 . We also calculated the odds ratios (OR), 95\% confidence intervals (CI) and the levels of significance. A $p$ value less than or equal to 0.05 was considered statistically significant. All of the genotype distributions were analyzed for Hardy-Weinberg equilibrium.

\section{Results and discussion}

The distribution of the cytochrome P450 genotypes and allele frequencies in the breast cancer patients

The cytochrome P450 genetic polymorphisms CYP2C8*2, CYP2C $8 * 3$, CYP2C9*2, CYP2C9*3, CYP2C19*2, CYP2C19*3, $C Y P 3 A 4 * 1 B, C Y P 3 A 4 * 2, C Y P 3 A 5 * 3$ and $C Y P 2 B 6 * 5$ were investigated in 395 female breast cancer patients. Table 2 shows the distribution of the cytochrome P450 genotypes and allele frequencies in the patients. The distribution of the genotype frequencies in breast cancer patients is in agreement with the expected frequencies for the majority of the investigated polymorphisms. Significant deviation from Hardy-Weinberg equilibrium was observed for CYP2C19*2 $(\mathrm{p}=0.003)$ and CYP2B6*5 $(\mathrm{p}=0.0008)$. This may be indicative of the functional significance of this locus or the variants being in non-equilibrium, linking this locus to breast cancer.

The frequencies of the $C Y P 2 C 8 * 2$ and $C Y P 2 C 8 * 3$ mutant alleles were $0.39 \%$ and $8.33 \%$ in the investigated group of breast cancer patients. According to the literature, the CYP2C $8 * 2$ allele is known to be found only in African Americans, which carry the allele at a frequency of $18 \%$, while the CYP2C8*3 mutant allele occurs primarily in Caucasians at a frequency of $13 \%$. Neither allele has so far been identified in Asians $[18,19]$.

In this group of breast cancer patients the frequency of the CYP2C9*2 and CYP2C9*3 mutant alleles was $10.36 \%$ 
Table 2 Genotype and allele frequencies of the CYP P450 genes in breast cancer patients

\begin{tabular}{|c|c|c|c|c|c|c|c|c|c|}
\hline \multirow[t]{2}{*}{ Nomenclature } & \multirow[t]{2}{*}{ rs } & \multirow[t]{2}{*}{ Nucleotide changes } & \multirow[t]{2}{*}{ Effect } & \multirow[t]{2}{*}{$\mathbf{n}$} & \multicolumn{3}{|c|}{ Genotype frequencies, $\%$} & \multicolumn{2}{|c|}{ Allele frequencies, $\%$} \\
\hline & & & & & wt & ht & vt & $p$ & $q$ \\
\hline CYP2C8*2 & rs11572103 & T805A & I269F & 383 & 99.22 & 0.78 & 0.00 & 99.61 & 0.39 \\
\hline CYP2C8*3 & rs11572080+ rs10509681 & $\mathrm{G} 416 \mathrm{~A}+\mathrm{A} 1196 \mathrm{G}$ & $\mathrm{R} 139 \mathrm{~K}+\mathrm{K} 399 \mathrm{R}$ & 390 & 83.85 & 15.64 & 0.51 & 91.67 & 8.33 \\
\hline CYP2C9*2 & rs1799853 & C430T & $\mathrm{R} 144 \mathrm{C}$ & 391 & 79.54 & 20.20 & 0.26 & 89.64 & 10.36 \\
\hline CYP2C9*3 & rs1057910 & A1075C & I359L & 394 & 81.22 & 17.77 & 1.02 & 90.10 & 9.90 \\
\hline CYP2C19*2 & rs4244285 & G681A & Splicing defect & 393 & 58.52 & 39.19 & 2.29 & 78.12 & 21.88 \\
\hline CYP2C19*3 & rs4986893 & G636A & W212X & 388 & 97.94 & 2.06 & 0.00 & 98.97 & 1.03 \\
\hline CYP3A4*1B & rs2740574 & A-392 G & 5'NTO change & 389 & 94.86 & 5.14 & 0.00 & 97.43 & 2.57 \\
\hline CYP3A4*2 & rs55785340 & T664C & S222P & 391 & 100.00 & 0.00 & 0.00 & 100.00 & 0.00 \\
\hline СYР $3 A 5 * 3$ & rs776746 & A6986G & $\mathrm{R} 487 \mathrm{C}$ & 392 & 0.26 & 11.99 & 87.76 & 6.25 & 93.75 \\
\hline CYP2B6*5 & rs3211371 & C1459T & Splicing defect & 390 & 85.64 & 12.56 & 1.79 & 91.92 & 8.08 \\
\hline
\end{tabular}

and $9.90 \%$, which was not significantly different from the number found in the literature for Caucasians, i.e., 8-19\% and $0-8.5 \%[1,7,20-23]$ for $C Y P 2 C 9 * 2$ and $C Y P 2 C 9 * 3$, respectively, but it is significantly higher than that found in African Americans, who carry the alleles at a frequency of $1 \%$ and $0.5 \%$, respectively. The CYP2C9*2 allele has not been detected in a Chinese population, and the frequency of the CYP2C9*3 allele was 2-2.6\% [22,24]. The CYP2C19*2 mutant allele was found at a frequency of $21.9 \%$ in this study, which is not significantly different from previous reports in the literature for Caucasians (15 20\%) [1,7] and Japanese (26.7\%) [25]. The CYP2C19*3 mutant allele frequency was $1.03 \%$ in our group of breast cancer patients, which was not different from the value found in

Table 3 Distribution of CYP2 genotypes and risk of neoadjuvant chemotherapy resistance developing in breast cancer patients

\begin{tabular}{|c|c|c|c|c|c|c|c|c|}
\hline \multirow[t]{2}{*}{ Polymorphism } & \multirow[t]{2}{*}{ Genotype } & \multicolumn{2}{|c|}{$\begin{array}{c}\text { Positive neoadjuvant } \\
\text { chemotherapy response }\end{array}$} & \multicolumn{2}{|c|}{$\begin{array}{l}\text { Negative neoadjuvant } \\
\text { chemotherapy response }\end{array}$} & \multirow[t]{2}{*}{ OR } & \multirow[t]{2}{*}{$\mathrm{Cl}(95 \%)$} & \multirow[t]{2}{*}{$p$} \\
\hline & & $\mathbf{n}$ & $\%$ & $\mathrm{n}$ & $\%$ & & & \\
\hline \multirow[t]{3}{*}{ CYP2B6*5 C1459T } & CC & 205 & 82.66 & 9 & 90.00 & 1.89 & $0.25-84.64$ & 0.99 \\
\hline & $\mathbf{C T}$ & 37 & 14.92 & 1 & 10.00 & 1.13 & $0.54-2.40$ & 0.99 \\
\hline & TT & 6 & 2.42 & 0 & 0.00 & 0.63 & $0.01-4.82$ & 0.99 \\
\hline \multirow[t]{3}{*}{ CYP2C8*2 T805A } & TT & 243 & 99.59 & 10 & 100.00 & 0.04 & $0.01-3.55$ & 0.08 \\
\hline & TA & 1 & 0.41 & 0 & 0.00 & 24.30 & $0.28-1914.18$ & 0.08 \\
\hline & AA & 0 & 0.00 & 0 & 0.00 & * & & \\
\hline \multirow[t]{3}{*}{ CYP2C8*3 G416A + A1196G } & GG & 203 & 82.19 & 6 & 60.00 & 0.33 & $0.07-1.64$ & 0.09 \\
\hline & GA & 44 & 17.81 & 4 & 40.00 & 3.08 & $0.61-13.53$ & 0.09 \\
\hline & AA & 0 & 0.00 & 0 & 0.00 & $*$ & & \\
\hline \multirow[t]{3}{*}{ CYP2C9*2 C430T } & CC & 204 & 82.26 & 5 & 50.00 & 0.22 & $0.05-0.99$ & 0.02 \\
\hline & CT & 44 & 17.74 & 5 & 50.00 & 4.64 & $1.01-20.91$ & 0.02 \\
\hline & TT & 0 & 0.00 & 0 & 0.00 & * & & \\
\hline \multirow[t]{3}{*}{ CYP2C9*3 A1075C } & $\mathbf{A A}$ & 211 & 84.40 & 8 & 80.00 & 0.74 & $0.14-7.41$ & 0.66 \\
\hline & AC & 36 & 14.40 & 1 & 10.00 & 0.66 & $0.01-5.03$ & 0.99 \\
\hline & CC & 3 & 1.20 & 1 & 10.00 & 9.15 & $0.16-124.95$ & 0.15 \\
\hline \multirow[t]{3}{*}{ CYP2C19*2 G681A } & GG & 136 & 54.62 & 8 & 66.67 & 3.32 & $0.64-32.61$ & 0.19 \\
\hline & GA & 109 & 43.78 & 2 & 16.67 & 0.32 & $0.03-1.66$ & 0.20 \\
\hline & AA & 4 & 1.61 & 2 & 16.67 & 6.13 & $0.11-69.01$ & 0.20 \\
\hline \multirow[t]{3}{*}{ CYP2C19*3 G636A } & GG & 241 & 97.97 & 10 & 100.00 & 0.21 & $0.02-10.78$ & 0.23 \\
\hline & GA & 5 & 2.03 & 0 & 0.00 & 4.82 & $0.09-48.97$ & 0.23 \\
\hline & AA & 0 & 0.00 & 0 & 0.00 & * & & \\
\hline
\end{tabular}

\footnotetext{
*- OR, Cl (95\%) and p-values were not applicable to these samples.
} 
Table 4 Distribution of CYP3 genotypes and risk of neoadjuvant chemotherapy resistance developing in breast cancer patients

\begin{tabular}{|c|c|c|c|c|c|c|c|c|}
\hline \multirow[t]{2}{*}{ Polymorphism } & \multirow[t]{2}{*}{ Genotype } & \multicolumn{2}{|c|}{$\begin{array}{l}\text { Positive neoadjuvant } \\
\text { chemotherapy response }\end{array}$} & \multicolumn{2}{|c|}{$\begin{array}{l}\text { Negative neoadjuvant } \\
\text { chemotherapy response }\end{array}$} & \multirow[t]{2}{*}{ OR } & \multirow[t]{2}{*}{$\mathrm{Cl}(95 \%)$} & \multirow[t]{2}{*}{$\mathrm{p}$} \\
\hline & & $\mathrm{n}$ & $\%$ & $\mathrm{n}$ & $\%$ & & & \\
\hline \multirow[t]{3}{*}{ CYP3A4*1B A-392 G } & AA & 234 & 94.74 & 9 & 90.00 & 0.04 & $0.01-3.47$ & 0.08 \\
\hline & AG & 13 & 5.26 & 1 & 10.00 & 24.90 & $0.29-1961.25$ & 0.08 \\
\hline & GG & 0 & 0.00 & 0 & 0.00 & $*$ & & \\
\hline \multirow[t]{3}{*}{ CYP3A4*2 T664C } & $\mathbf{T T}$ & 249 & 100.00 & 10 & 100.00 & $*$ & & \\
\hline & TC & 0 & 0.00 & 0 & 0.00 & * & & \\
\hline & CC & 0 & 0.00 & 0 & 0.00 & * & & \\
\hline \multirow[t]{3}{*}{ CYP3A5*3 A6986G } & AA & 0 & 0.00 & 0 & 0.00 & $*$ & & \\
\hline & AG & 33 & 13.31 & 1 & 10.00 & 0.72 & $0.02-5.53$ & 0.99 \\
\hline & GG & 215 & 86.69 & 9 & 90.00 & 1.38 & $0.18-62.36$ & 0.99 \\
\hline
\end{tabular}

*- OR, Cl (95\%) and p-values were not applicable to these samples.

the literature data for Caucasians $(0.0 \%)$ or Asians (3.75\%) [26]. This allele occurs only in heterozygocity. None of the investigated patients were homozygotes for the CYP2C19*3 allele. The CYP2B6*5 mutant allele frequency was $8.1 \%$, which was not significantly lower than the published value for Caucasians (9.1\%) and higher than that published for Asians (4.2\%).

The frequency of the $C Y P 3 A 4 * 1 B$ mutant allele was $2.57 \%$ in this group of breast cancer patients; the literature reports significant interethnic variations in this allele $(2-9 \%$ for Caucasians, 35-66\% for African Americans and 0\% for Taiwanese and Chinese [27]). The CYP3A $4 * 2$ mutant allele was not present in the investigated group of breast cancer patients, while in its frequency in Caucasians ranges from $1.1 \%$ in a German population to $4.5 \%$ in a Portuguese population [28].

The frequency of the CYP $3 A 5 * 3$ polymorphic allele in the total population sampled was $93.75 \%$. This agrees with the previously published data, which reports a total frequency of the $C Y P 3 A 5 * 3$ allele of $91.7-94.2 \%$ in Caucasians $[14,27,29]$ and $66.7-75 \%$ in Asians [30].

The cytochrome $\mathrm{P} 450$ polymorphisms and the chemotherapy efficacy in the breast cancer patients Table 3 shows the distribution of the polymorphic variants of the analyzed genes in the breast cancer patients along

Table 5 Risk of chemotherapy resistance in breast cancer patients with different CYP2C9*2 genotypes and tumour characteristics

\begin{tabular}{|c|c|c|c|c|c|c|c|c|}
\hline \multirow[t]{2}{*}{ Group } & \multirow{2}{*}{$\begin{array}{c}\text { Allele/ } \\
\text { Genotype } \\
\text { CYP2C9*2 } \\
\text { C430T }\end{array}$} & \multicolumn{2}{|c|}{$\begin{array}{c}\text { Positive neoadjuvant } \\
\text { chemotherapy response }\end{array}$} & \multicolumn{2}{|c|}{$\begin{array}{l}\text { Negative neoadjuvant } \\
\text { chemotherapy response }\end{array}$} & \multirow[t]{2}{*}{ OR } & \multirow[t]{2}{*}{$\mathrm{Cl}(95 \%)$} & \multirow[t]{2}{*}{$\mathbf{p}$} \\
\hline & & $n$ & $\%$ & $n$ & $\%$ & & & \\
\hline \multirow[t]{5}{*}{ Cancer hereditary load } & C & 167 & 91.76 & 7 & 70.00 & 4.77 & $0.71-23.47$ & 0.055 \\
\hline & $\mathbf{T}$ & 15 & 8.24 & 3 & 30.00 & & & \\
\hline & CC & 76 & 83.52 & 2 & 40.00 & 0.13 & $0.01-1.29$ & 0.04 \\
\hline & CT & 15 & 16.48 & 3 & 60.00 & 7.60 & $0.78-95.24$ & 0.04 \\
\hline & TT & 0 & 0.00 & 0 & 0.00 & * & & \\
\hline \multirow[t]{5}{*}{ Nodal form } & C & 371 & 91.83 & 10 & 71.43 & 4.50 & $0.97-16.60$ & 0.027 \\
\hline & $\mathbf{T}$ & 33 & 8.17 & 4 & 28.57 & & & \\
\hline & CC & 169 & 83.66 & 3 & 42.86 & 0.15 & $0.02-0.92$ & 0.019 \\
\hline & CT & 33 & 16.34 & 4 & 57.14 & 6.83 & $1.09-48.12$ & 0.019 \\
\hline & TT & 0 & 0.00 & 0 & 0.00 & * & & \\
\hline \multirow[t]{5}{*}{ Cancer hereditary load + nodal form } & C & 136 & 91.89 & 3 & 50.00 & 11.33 & $1.32-91.23$ & 0.01 \\
\hline & $\mathbf{T}$ & 12 & 8.11 & 3 & 50.00 & & & \\
\hline & CC & 62 & 83.78 & 0 & 0.00 & 0.06 & $0.01-0.91$ & 0.02 \\
\hline & CT & 12 & 16.22 & 3 & 100.00 & 15.50 & $1.08-826.12$ & 0.02 \\
\hline & TT & 0 & 0.00 & 0 & 0.00 & * & & \\
\hline
\end{tabular}

*- OR, $\mathrm{Cl}(95 \%)$ and p-values were not applicable to these samples. 
with the known efficacy of the neoadjuvant chemotherapy for the CYP2 family. The study of the association of the CYP2B6*5, CYP2C8*2, CYP2C8*3, CYP2C9*2, CYP2C9*3, CYP2C19*2 and CYP2C19*3 variants with a negative response to neoadjuvant chemotherapy in breast cancer patients included an odds ratio evaluation indicating the probability of poor chemotherapeutic efficacy in individuals with certain genotypes. The observed distribution of the most common genotypes in breast cancer patients are in Hardy-Weinberg equilibrium with the exception of CYP2B6*5 ( $\mathrm{p}=0.0198)$ and CYP19*2 $(\mathrm{p}=0.0003)$. The enrichment of the CYP2B6*5 and CYP19*2 alleles in this group may be due to the population possessing its own pool of alleles, resulting in different frequencies of unfavorable alleles. The risk of an insufficient response to breast cancer neoadjuvant chemotherapy in $C Y P 2 C 9 * 2$ heterozygotes was 4.64 -fold higher $(\mathrm{OR}=$ 4.64, $\mathrm{p}=0.02$ ) than in patients with the wild type allele. The impaired efficacy of neoadjuvant chemotherapy in patients containing the CYP2C9*2 mutant allele might be a result of the enzymatic activity of CYP2C9, which is involved into the chain reaction responsible for the conversion of the cyclophpsphamide prodrug into an active metabolite [29,30].

The risk of poor neoadjuvant chemotherapy efficacy is much higher in CYP2C8 $* 2$ heterozygotes $(\mathrm{OR}=24.30)$ and slightly higher in $C Y P 2 C 8 * 3$ heterozygotes $(\mathrm{OR}=3.08)$ at a level of statistical significance close to the proposed level $(\mathrm{p}=0.08$ and $\mathrm{p}=0.09$, respectively, versus $\mathrm{p}<0.05$ ). Furthermore, the CYP2C9*3 (OR =9.15) and CYP2C19*2 $(\mathrm{OR}=6.13)$ mutant type genotypes and heterozygotic CYP2C19*3 $(\mathrm{OR}=4.82)$ genotype are associated with a low efficacy of neoadjuvant chemotherapy; however, these associations were not found to be statistically significant (p>0.05). It appears that the CYP2B6*5, CYP2C8*2, CYP2C8*3, CYP2C9*3, CYP2C19*2 and CYP2C19*3 mutant alleles are not a factor in resistance to neoadjuvant chemotherapies in breast cancer patients.

Table 4 shows the distribution of the polymorphic variants of the genes studied here in breast cancer patients along with the known efficacy of the neoadjuvant chemotherapy for the CYP3 family. Gene polymorphisms association with neoadjuvant chemotherapy efficacy were analyzed for the CYP $3 A 4 * 1 B$ and CYP3A5*3 polymorphisms. CYP $3 A 4 \% 2$ was not included in the study because no heterozygotes or homozygotes containing the CYP3A4*2 mutant allele were found in the population. For $C Y P 3 A 4 * 1 B$ heterozygotes, the risk of a negative response to neoadjuvant chemotherapy is 24.9 -fold higher than in carriers of the wild type allele, which has a level of significance $(\mathrm{p}=0.08)$ that approaches the significance threshold $(\mathrm{p}=0.05)$. No significant association between CYP3A5*3 genotypes and chemotherapy resistance were discovered.
The analyses performed here cover the distribution of cytochrome genetic polymorphisms and their association with the known efficacy of neoadjuvant chemotherapy in breast cancer patients known to have a cancer hereditary load (cancer cases in patient's relatives), a clinical form of cancer, degree of malignancy and histological type of tumour. In CYP2C9*2 heterozygotes with a high hereditary load, the risk of tumour resistance to neoadjuvant chemotherapy was 7.6-fold higher than wild type homozygotes $(\mathrm{OR}=7.6, \mathrm{p}=0.04)$ (Table 5). A similar association was observed in patients with the nodal form of breast cancer. The risk of tumour resistance to chemotherapy for CYP2C9*2 heterozygotes was 6.83 -fold higher than in wild type homozygotes (Table 5; OR $=6.83, \mathrm{p}=0.019$ ). In CYP2C9*2 heterozygotes with nodal form of cancer and a cancer hereditary load, the risk of resistance to chemotherapy was 15.5 -fold higher than those with the wild type genotype $(\mathrm{OR}=15.5, \mathrm{p}=0.02)$. Patients with other clinical features and genetic variants of the investigated cytochromes showed no statistically important association with neoadjuvant chemotherapy efficacy.

\section{Conclusions}

CYP2C9*2 polymorphism is associated with neoadjuvant chemotherapy efficacy in breast cancer patients $(\mathrm{OR}=4.64$; CI 95\% $=1.01-20.91)$.

\section{Competing interests}

The authors declare that they have no competing interests.

\section{Authors' contributions}

TAS, OBG, VOT carried out the molecular genetic studies, performed the statistical analysis and drafted the manuscript. AYUG and WL conceived of the study, and participated in its design and coordination and conducted data acquisition. All authors read and approved the final manuscript.

\section{Acknowledgements}

This work was funded by Russian Academy of Medical Sciences (SB RAMS) Program "Molecular-genetic mechanisms of formation and progression of breast cancer: development of the risk criterion, prognosis for the disease and chemotherapy efficacy on the basis of informative tumour markers identification".

The authors are grateful to Litvyakov CN, Garbukov EYu and Cherdyntseva NV from Tomsk Cancer Research Institute in the Tomsk Scientific Center of the RAMS for providing of genomic DNA and clinical date of the breast cancer patients.

Received: 1 February 2012 Accepted: 22 May 2012

Published: 15 June 2012

\section{References}

1. Bray J, Sludden J, Griffin MJ, Cole M, Verrill M, Jamieson D, Boddy AV: Influence of pharmacogenetics on response and toxicity in breast cancer patients treated with doxorubicin and cyclophosphamide. Br J Cancer 2010, 102(6):1003-1009.

2. Wang L, Ellsworth KA, Moon I, Pelleymounter LL, Eckloff BW, Martin YN, Fridley BL, Jenkins GD, Batzler A, Suman VJ, Ravi S, Dixon JM, Miller WR, Wieben ED, Buzdar A, Weinshilboum RM, Ingle JN: Functional genetic polymorphisms in the aromatase gene CYP19 vary the response of breast cancer patients to neoadjuvant therapy with aromatase inhibitors. Cancer Res 2010, 70(1):319-328.

3. Ruiter R, Bijl MJ, van Schaik RH, Berns EM, Hofman A, Coebergh JW, van Noord C, Visser LE, Stricker BH: CYP2C19*2 polymorphism is associated 
with increased survival in breast cancer patients using tamoxifen. Pharmacogenomics 2010, 11(10):1367-1375.

4. Dees EC, Watkins PB: Role of cytochrome P450 phenotyping in cancer treatment. J Clin Oncol 2005, 23(6):1053-1055.

5. Zhang J, Tian Q, Zhou S: Clinical Pharmacology of Cyclophosphamide and Ifosfamide. Current Drug Therapy 2006, 1:55-84.

6. Rodriguez-Antona C, Ingelman-Sundberg M: Cytochrome P450 pharmacogenetics and cancer. Oncogene 2006, 25(11):1679-1691.

7. Robert J, Morvan VL, Smith D, Pourquier P, Bonnet J: Predicting drug response and toxicity based on gene polymorphisms. Crit Rev Oncol Hematol 2005, 54(3):171-196.

8. van Schaik RH: Cancer treatment and pharmacogenetics of cytochrome P450 enzymes. Invest New Drugs 2005, 23(6):513-522.

9. de Morais SM, Wilkinson GR, Blaisdell J, Nakamura K, Meyer UA, Goldstein JA: The major genetic defect responsible for the polymorphism of S-mephenytoin metabolism in humans. J Biol Chem 1994, 269(22):15419-15422.

10. Daly AK: Pharmacogenetics of the major polymorphic metabolizing enzymes. Fundam Clin Pharmacol 2003, 17(1):27-41.

11. Lang T, Klein K, Fischer J, Nüssler AK, Neuhaus P, Hofmann U, Eichelbaum $M$, Schwab M, Zanger UM: Extensive genetic polymorphism in the human CYP2B6 gene with impact on the expression and function in human liver. Pharmacogenetics 2001, 11(5):399-415.

12. Westlind A, Löfberg L, Tindberg N, Andersson TB, Ingelman-Sundberg M: Interindividual differences in hepatic expression of CYP3A4: relationship to genetic polymorphism in the 5 '-upstream regulatory region. Biochem Biophys Res Commun 1999, 259(1):201-205.

13. Busi F, Cresteil T: CYP3A5 mRNA degradation by nonsense-mediated mRNA decay. Mol Pharmacol 2005, 68(3):808-815.

14. van Schaik RH, van der Heiden IP, van den Anker JN, Lindemans J: CYP3A5 variant allele frequencies in Dutch Caucasians. Clin Chem 2002, 48(10):1668-1671.

15. Ramenskaya GV, Smoliarchuk EA, Kukes VG: Investigation of effect CYP3A4 polymorfpism on pharmacokinetics and clinical efficiency of verapamil. Bull Exp Biol Med 2002, 138(9):71-73.

16. Yilmaz N, Erbagci AB, Aynacioglu AS: Cytochrome P4502C9 genotype in Southeast Anatolia and possible relation with some serum tumour markers and cytokines. Acta Biochim Pol 2001, 48(3):775-782.

17. Seredina TA, Goreva OB, Talaban VO, Grishanova AYu, Litvyakov NV, Garbukov EYu, Lyakhovich W: Investigation of association of cytochrome P4502C genetic polymorphism with neoadjuvant chemotherapy efficiency in breast cancer patients. Vestnik Novosibirsk state university. Series: biology and clinical medicine 2008, 6(3):19-24.

18. Dai D, Zeldin DC, Blaisdell JA, Chanas B, Coulter SJ, Ghanayem Bl, Goldstein JA: Polymorphisms in human CYP2C8 decrease metabolism of the anticancer drug paclitaxel and arachidonic acid. Pharmacogenetics 2001, 11(7):597-607.

19. Bahadur N, Leathart JB, Mutch E, Steimel-Crespi D, Dunn SA, Gilissen R, Houdt JV, Hendrickx J, Mannens G, Bohets H, Williams FM, Armstrong M, Crespi CL, Daly AK: CYP2C8 polymorphisms in Caucasians and their relationship with paclitaxel 6alpha-hydroxylase activity in human liver microsomes. Biochem Pharmacol 2002, 64(11):1579-1589.

20. Sullivan-Klose TH, Ghanayem BI, Bell DA, Zhang ZY, Kaminsky LS, Shenfield GM, Miners JO, Birkett DJ, Goldstein JA: The role of the CYP2C9-Leu359 allelic variant in the tolbutamide polymorphism. Pharmacogenetics 1996, 6(4):341-349.

21. Sandberg M, Johansson I, Christensen M, Rane A, Eliasson E: The impact of CYP2C9 genetics and oral contraceptives on cytochrome P450 2 C9 phenotype. Drug Metab Dispos 2004, 32(5):484-489.

22. Sekine I, Saijo N: Polymorphisms of metabolizing enzymes and transporter proteins involved in the clearance of anticancer agents. Ann Oncol 2001, 12(11):1515-1525.

23. Fukushima-Uesaka H, Saito Y, Maekawa K, Ozawa S, Hasegawa R, Kajio H, Kuzuya N, Yasuda K, Kawamoto M, Kamatani N, Suzuki K, Yanagawa T, Tohkin M, Sawada J: Genetic variations and haplotypes of CYP2C19 in a Japanese population. Drug Metab Pharmacokinet 2005, 20(4):300-307.

24. Gan CQ, Wang XY, Cao YD, Ye WX, Liu H, Sun YY: Association of CYP2C19*3 gene polymorphism with breast cancer in Chinese women. Genet Mol Res 2011, 10(4):3514-3519.

25. Gor PP, Su HI, Gray RJ, Gimotty PA, Horn M, Aplenc R, Vaughan WP, Tallman MS, Rebbeck TR, DeMichele A: Cyclophosphamide-metabolizing enzyme polymorphisms and survival outcomes after adjuvantchemotherapy for node-positive breast cancer: a retrospective cohort study. Breast Cancer Res 2010, 12(3):R26.

26. Sata F, Sapone A, Elizondo G, Stocker P, Miller VP, Zheng W, Raunio H, Crespi CL, Gonzalez FJ: CYP3A4 allelic variants with amino acid substitutions in exons 7 and 12: evidence for an allelic variant with altered catalytic activity. Clin Pharmacol Ther 2000, 67(1):48-56.

27. Henningsson A, Marsh S, Loos WJ, Karlsson MO, Garsa A, Mross K, Mielke S, Viganò L, Locatelli A, Verweij J, Sparreboom A, McLeod HL: Association of CYP2C8, CYP3A4, CYP3A5, and ABCB1 polymorphisms with the pharmacokinetics of paclitaxel. Clin Cancer Res 2005, 11(22):8097-8104.

28. Lee SJ, Goldstein JA: Functionally defective or altered CYP3A4 and CYP3A5 single nucleotide polymorphisms and their detection with genotyping tests. Pharmacogenomics 2005, 6(4):357-371.

29. Timm R, Kaiser R, Lötsch J, Heider U, Sezer O, Weisz K, Montemurro M, Roots I, Cascorbi I: Association of cyclophosphamide pharmacokinetics to polymorphic cytochrome P450 2 C19. Pharmacogenomics J 2005, 5(6):365-373.

30. DeMichele A, Aplenc R, Botbyl J, Colligan T, Wray L, Klein-Cabral M, Foulkes A, Gimotty P, Glick J, Weber B, Stadtmauer E, Rebbeck TR:

Drug-metabolizing enzyme polymorphisms predict clinical outcome in a node-positive breast cancer cohort. J Clin Oncol 2005, 23(24):5552-5559.

doi:10.1186/1471-2350-13-45

Cite this article as: Seredina et al:: Association of cytochrome P450 genetic polymorphisms with neoadjuvant chemotherapy efficacy in breast cancer patients. BMC Medical Genetics 2012 13:45.

\section{Submit your next manuscript to BioMed Central and take full advantage of:}

- Convenient online submission

- Thorough peer review

- No space constraints or color figure charges

- Immediate publication on acceptance

- Inclusion in PubMed, CAS, Scopus and Google Scholar

- Research which is freely available for redistribution 